\title{
An experimental investigation into enhancing oil recovery using combination of new green surfactant with smart water in oil-wet carbonate reservoir
}

\author{
Omid Mosalman Haghighi ${ }^{1}$. Ali Mohsenatabar Firozjaii ${ }^{1}$
}

Received: 10 May 2019 / Accepted: 16 July 2019 / Published online: 23 July 2019

(c) The Author(s) 2019

\begin{abstract}
Enhancing oil recovery from oil-wet carbonate oil reservoir is an important challenge in the world, especially in Middle East oil field. Surfactant and smart water can change the interfacial tension and wettability condition of this type of rock to water wet from oil wet. The present study follows the experimental work of the combination of new green surfactant with smart water to enhance oil recovery from a carbonate oil-wet rock. Wettability alternation and IFT reduction by surfactant, smart water and combination of surfactant with smart water were investigated experimentally. The results show that making surfactant solution using smart water can reduce oil saturation by reducing IFT and alter wettability conditions. The oil recovery factor at the end of water, surfactant and surfactant-smart water flooding was 36,52 and $66 \%$, respectively. It shows that combination of surfactant with smart water can help surfactant to be powerful.
\end{abstract}

Keywords Wettability alteration $\cdot$ Surfactant $\cdot$ Smart water $\cdot$ Oil wet $\cdot$ IFT

\section{Introduction}

The industrial developing increase the world energy demand to follow their growing industries running. To meet the world energy demand, it is essential to grow the hydrocarbon reserves and production. It is possible to increase oil production by developing mature reservoirs or discovering new reservoirs. In most cases, it is economical to develop mature reservoirs (Mohsenatabar Firozjaii et al. 2019). Increasing oil production from mature reservoir is an interesting work for petroleum industry researchers. There are some methods to enhance oil recovery from mature reservoir after primary and secondary oil production stages (Onyekonwu and Ogolo 2010). These methods are called enhancing oil recovery or EOR process. The EOR process is classified into four main groups, which include thermal, chemical, miscible gas and microbial (Sheng 2010). Although these methods are expensive and not always operative, researchers are particularly attentive to increase oil production by this techniques, but

Ali Mohsenatabar Firozjaii

ali_mohsen_tabar@yahoo.com

1 Department of Petroleum Engineering, Petroleum University of Technology, Abadan, Iran tertiary recovery can still be money-making if market fees for oil are high sufficiently (Hirasaki and Zhang 2004). The studies concerned with EOR showed $11 \%$ of the EOR project in worldwide forced on chemical enhancing oil recovery (Rellegadla et al. 2017). The chemical enhanced oil recovery methods or CEOR are beneficial for light oil reservoir (Alvarado and Manrique 2010). Generally, CEOR are applied in the formation with two main goals: reducing the interfacial tension (IFT) between the reservoir oil and the injected fluid and improving the sweep efficiency of the injected fluid by decreasing mobility of injected fluid (Shah 2012). The IFT reduction and wettability alteration are occurred by adding some surface agent material (Xie et al. 2005). Optimizing oil recovery is strongly depending on oil reservoir formation wettability and IFT between oil and water on rock surface. When an enhancing oil recovery method, particularly related to water flooding, is considered to apply on reservoir, the surface wetting condition of the formation influences the performance of process and determines the final recovery and cost during oil recovery (Hirasaki and Zhang 2004). When two immiscible fluids are presented on a solid surface, one of them would like to spread on the surface compared to another. When a solid-oil-water system is created in porous media, there is a balance of two-liquid phase with solid surface (Mittal 2009). As shown in Fig. 1, the below 


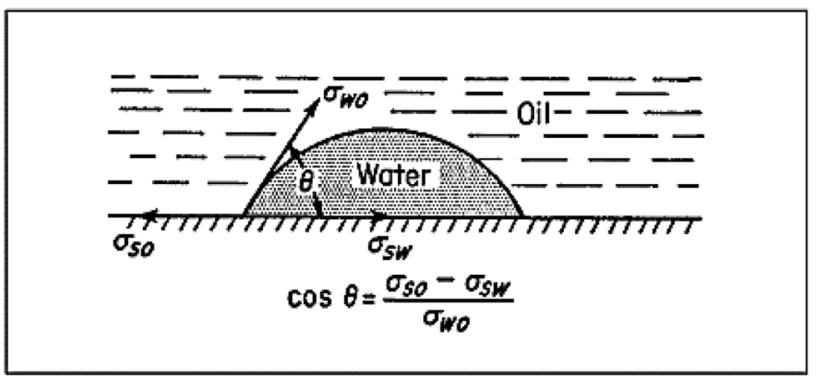

Fig. 1 The IFT for solid-oil-water system at balance (Mittal 2009)

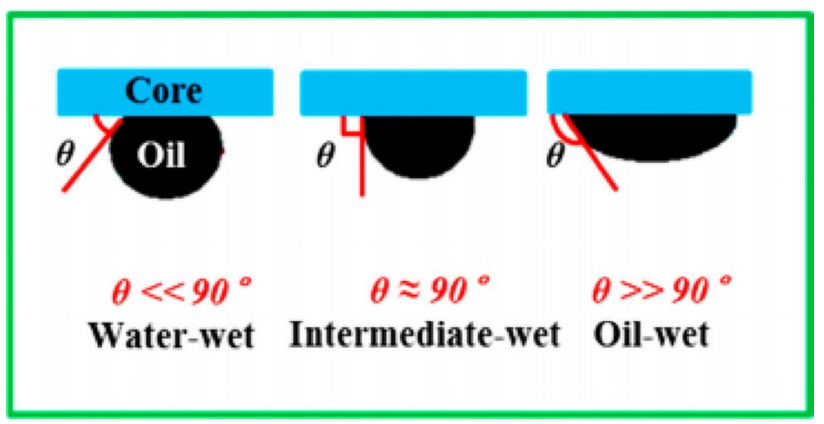

Fig. 2 A schematic diagram of rock wettability conditions (Sun et al. 2017)

equation (known as Young's equation) shows the balance of solid-oil-water system:

$\sigma_{\mathrm{SO}}-\sigma_{\mathrm{SW}}=\sigma_{\mathrm{SO}} \cos (\theta)$

where $\sigma_{\mathrm{sw}}$ is the IFT between the water and solid, $\sigma_{\mathrm{so}}$ is the IFT between the oil and solid, and $\sigma_{\text {wo }}$ is surface tension between the oil and water. $\theta$ is the contact angle measured through the water phase.

In the reservoir where oil and water exist together, there will be water-wet and oil-wet systems. Oil phase is spread on the grain surfaces while the water phase is located in the pore bodies (Mittal 2009). A reservoir may have mixwet condition when smaller pores are filled with oil and are water wet, whereas larger pores are filled with oil and are oil wet (Kathel and Mohanty 2013). As shown in Fig. 2, the wettability condition on solid-liquid system is often distinguished using the contact angle of the liquid phase on solid surface (Sun et al. 2017). Wettability has a significant effect on the production of oil and gas. By changing wettability condition from oil to water wet or by reducing IFT, the residual oil saturation decreases. Adding some surface agent material such as surfactant or changing the surface condition of rock provides more oil recovery (Sun et al. 2017). When surfactant is solved in water and then is injected to reservoir, interfacial tension (IFT) is decreased. As shown in below equation, IFT reduction can increase capillary number. As

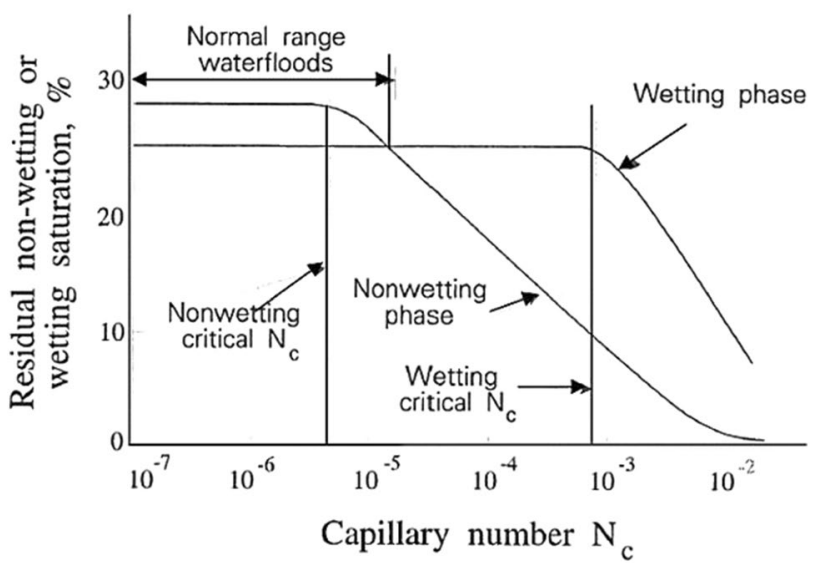

Fig. 3 The relationship between capillary number and residual oil saturation (Firozjaii et al. 2018)

shown in Fig. 3, residual oil saturation has strong dependence on capillary number $\left(N_{\mathrm{c}}\right)$, in which by raising $\mathrm{Nc}$, the oil saturation is decreased (Firozjaii et al. 2018). The most efficient IFT reduction will happen at the critical micelle concentration (CMC). At CMC point, the surfactant monomers existing in the emulsion have the highest possible concentration, thus reducing the IFT most (Puerto 2001).

$N_{\mathrm{c}}=\frac{u \times \mu}{\delta}$

where $\delta$ is IFT, $\mu$ is fluid viscosity, and $u$ is fluid velocity.

Surfactant flooding is a popular chemical enhancing oil recovery methods that some researchers focused on it at oilwet rock (Strand 2003; Seethepalli et al. 2004; SayedAkram and Mamora 2011; Firozjaii et al. 2018). Nowadays natural surfactants have become a substitute for industrial surfactant because of environmental friendly and low cost of production (Ghahfarokhi et al. 2015; Mehdi et al. 2015). Recently, some researcher focused on using nanoparticle combination with surfactant to improve oil recovery and surfactant flooding efficiency (Bagrezaie and Pourafshary 2015; Emadi et al. 2017). Using surfactant is not limited to CEOR process. It is interesting that mentioned surfactant can be used in hydraulic fracturing or completion fluid due to wettability alteration and IFT reduction (Zhang et al. 2018).

Recently, more attention has been exposed in advanced water floods for oil-recovery enhancement in the reservoir engineering. Brine water (brine) flooding can produce oil from porous media (Ligthelm et al. 2009). Adding some ions can help the efficiency of water flooding (Tang and Morrow 1999). Injection water salinity can change the rock surface wettability as surfactant (RezaeiDoust et al. 2009). Low salinity and smart water flooding were presented more than two decades ago. In this case, presence of dual ions $\left(\mathrm{Ca}^{2+}, \mathrm{Mg}^{2+}\right.$, and $\left.\mathrm{So}_{4}^{2-}\right)$ changes the wettability of rock from 


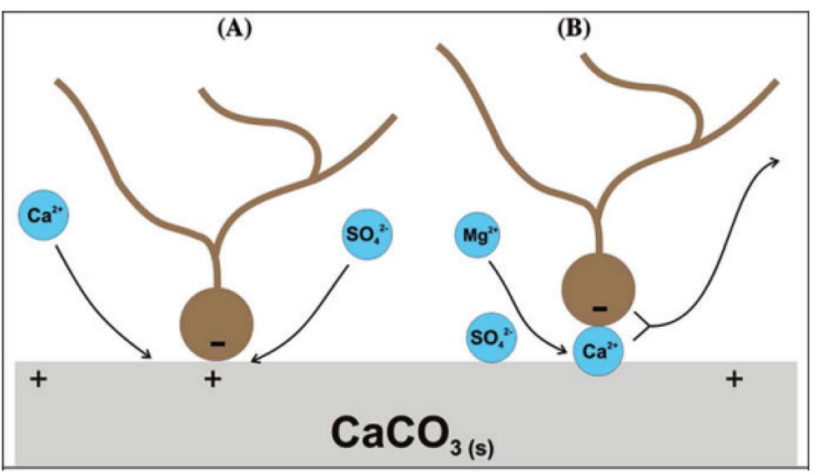

Fig. 4 Schematic model of the wettability alteration induced by sea water. a Proposed mechanism when $\mathrm{Ca}^{2+}$ and $\mathrm{SO}_{4}{ }^{2-}$ are active. b Proposed mechanism when $\mathrm{Mg}^{2+}$ and $\mathrm{SO}_{4}{ }^{2-}$ are active (Zhang et al. 2007)

oil wet to water wet in a carbonate rock (Fathi et al. 2010). Based on some experimental results, wettability alteration was proposed to be a key reason for the improvement of the oil recovery (Strand et al. 2008; Yousef et al. 2011; Fathi et al. 2012; Puntervold et al. 2015). Figure 4 shows the chemical mechanism for wettability modification during sea water injection. Therefore, choosing the best concentration of ions in water can control the wettability alteration or contact angle (Yousef et al. 2011). Smart water is actually a seawater in which its composition is optimized in terms of ionic composition and the amount of salinity (Awolayo et al. 2014). Some research has been about modified sea water as smart water for EOR (RezaeiDoust et al. 2009; SayedAkram and Mamora 2011; Seethepalli et al. 2004; Shah 2012). For example, Webb et al. (2005) investigated a comparative experiment on the oil recovery from a carbonate core with seawater which holds $\mathrm{SO}^{2-}$ at reservoir conditions and simulated $\mathrm{SO}^{2-}$ free brine. It was determined that the wettability alteration of the carbonate rock with $\mathrm{SO}_{4}{ }^{2-}$ ion is responsible for the saturation changes (Webb et al. 2005). Widespread laboratory research has been applied in order to recognize EOR from chalk using surfactant solutions and later on using modified sea water. This ion must act together with $\mathrm{Ca}^{2+}$ and $\mathrm{Mg}^{2+}$ because sulfate alone is not capable to increase spontaneous imbibition. The results showed wettability alteration toward more water-wetting conditions to be the only reason for EOR with these seawater ions (Fathi et al. 2010).

In the present study, wettability alteration and IFT reduction are considered in oil-wet carbonate rock by using combination of smart water and a new green surfactant. The contact angle measurement method is used for detecting wettability alteration. The pendant drop method is employed to measure IFT change. Then, the core flooding is applied rock plug at optimum concentration of surfactant and smart water.
Table 1 The crude oil properties

Density@25C 0.878 gr/cc and 14.7 Psi

Viscosity @ 25C $13.23 \mathrm{cP}$ and 14.7 Psi

API

32.6

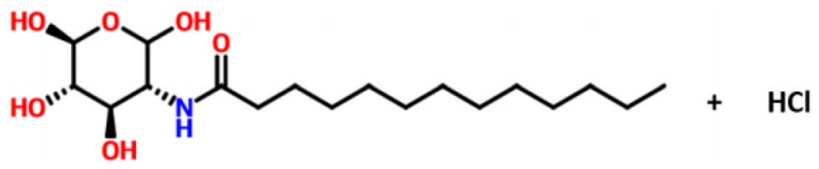

Fig. 5 The structure of dodecanoylglucosamine (Omid et al. 2018)

\section{Materials}

The crude oil used in this study was provided from Ahwaz oilfield from Iran. This oil is classified as light crude oil with approximately an API gravity of 32.6. Table 1 shows the properties of this crude oil. The synthetic brines were composed of a mixture of salt $(\mathrm{NaCl})$ and de-ionized water at 100,000 ppm. The new type of nonionic surfactant called dodecanoylglucosamine that also has medical applications is considered for wettability alteration and IFT reduction. This surfactant was synthesized by Mosalman Haghighi et al. (2018) at Petroleum University of Technology (Abadan, Iran) by mixture of glucosamine, methanol and dodecanoyl chloride (Omid et al. 2018). Figure 5 shows the structure of this green surfactant. For preparing the smart water, the salts were provided by the German Merck Company which include $\mathrm{NaCl}, \mathrm{MgCl}_{2} \cdot 6 \mathrm{H}_{2} \mathrm{O}, \mathrm{NaHCO}_{3}, \mathrm{CaCl}_{2} \cdot 2 \mathrm{H}_{2} \mathrm{O}$ and $\mathrm{Na}_{2} \mathrm{SO}_{4}$ with a purity higher than $99 \%$. The rock plug sample was obtained from Asmari formation. Although most of carbonate rocks have low permeability, sample used in this project is porous and permeable. The properties of the plug are summarized in Table 2.

\section{Experimental}

\section{Surfactant solution preparing}

Various solutions of the surfactant samples in distilled water were prepared in the range of 100 to $10,000 \mathrm{ppm}$. The $\mathrm{pH}$ and conductivity of solution were measured using $\mathrm{pH}$ and conductivity meters. These measurements were applied to determine the CMC of surfactant solution. The interfacial tension measurement tests were performed to obtain the tension between two liquid phases at ambient temperature and pressure. All IFT tests were performed in an ambient temperature of $25^{\circ} \mathrm{C}$ and

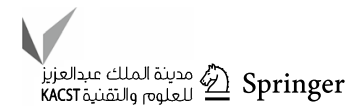


Table 2 The properties of rock sample

\begin{tabular}{ll}
\hline Length $(\mathrm{cm})$ & 7.74 \\
Diameter $(\mathrm{cm})$ & 3.69 \\
Dry weight $(\mathrm{gr})$ & 188.6 \\
Wet weight $(\mathrm{gr})$ & 202.1 \\
Pore volume (cc) & 12.63 \\
Bulk volume (cc) & 85.6 \\
Porosity (\%) & 14.7 \\
Permeability (mD) & 8.16 \\
Original oil in place (OOIP, cc) & 9.35 \\
Connate water saturation (\%) & 26 \\
Initial oil saturation $(\%)$ & 74 \\
\hline
\end{tabular}

atmospheric pressure condition. Because of apparatus limitation, kerosene was used as the oil phase in all tests. Meanwhile, the acid group was added to the kerosene to reach the reservoir condition. The pendant drop method is considered for detecting IFT using VIT-6000. In this way, video images of the pendant drops are used to determine the interface characteristics, and then IFT measurements are digitized through the solution of the Young-Laplace equation. For measuring the wettability alteration, some pellet was made from carbonate rock sample. The pellets were put in oil at $85{ }^{\circ} \mathrm{C}$ to be aged with oil for 2 weeks. Then, the wettability of pellet was measured by contact angle measurement using VIT 6000. Then the pellets were put in different concentration of the surfactant solutions for 10 days. The wettability alteration on rock pellets by surfactant solution was measured using contact angle measurement.

\section{Smart water preparing}

The synthetic brine solutions were prepared by spiking the different amounts of $\mathrm{MgCl}_{2} \cdot 6 \mathrm{H}_{2} \mathrm{O}, \mathrm{NaCl}, \mathrm{NaHCO}_{3}, \mathrm{CaCl}_{2} \cdot 2 \mathrm{H}_{2} \mathrm{O}$ and $\mathrm{Na}_{2} \mathrm{SO}_{4}$ to the deionized water and were mixed in calculated proportion based on stoichiometry. First the synthetic sea water (SW) was prepared with total dissolve solid (TDS) 43,091 ppm. Table 3 shows the ions concentration in sea water. Then, the concentration of each ion includes sulfate, magnesium and calcium modified from $0,2,4$ and 6 times. The contact angle of some oil aged pellets was measured at different concentrations of ions of modified SW.

\section{Surfactant solution with smart water}

After detecting the CMC of surfactant, the new solution of surfactant was prepared by using modifying SW at the concentration of each ion which includes sulfate, magnesium and calcium modified from 0, 2, 4 and 6 times. The contact angle and IFT solutions were measured to detect the effect of ions on surfactant solution behavior.

\section{Core flooding}

The core flooding experiment was performed to evaluate the effectiveness of surfactant, smart water and combination of smart water and surfactant in altering wettability of carbonate reservoirs and oil recovery. First, the prepared and clean rock plug was kept by core holder. The overburden pressure 2500 psi was set by handing pump. The brine water was injected to core with different injection rates to determine the absolute permeability. Then, the crude oil was injected in core by various rates to reach connate water saturation. The results of connate water and initial oil saturation in rock plug are presented in Table 2. Three scenarios of flooding were considered to apply on core. First water flooding using brine water was employed to recover oil as secondary oil recovery. Then, the core was removed from core holder and clean and washed. The core flooding condition was prepared again to flood surfactant as tertiary oil recovery. Then, the core was prepared again to flood. Finally, combination of surfactant with smart water was applied on core. All flooding was applied at constant rate $0.2 \mathrm{cc} / \mathrm{min}$.

\section{Results and discussion}

\section{Surfactant behavior}

The CMC of surfactant solution was obtained based on $\mathrm{pH}$ and conductivity. As shown in Fig. 6, the $\mathrm{pH}$ of surfactant solution was decreased by increasing surfactant concentration. This reduction shows acetic behavior of the surfactant. On the other hand, the conductivity of solution was raised by increasing surfactant concentration (Fig. 7). This behavior is depended on chemical structure of dodecanoylglucosamine. The CMC was $800 \mathrm{ppm}$ from $\mathrm{pH}$ and conductivity.

As shown in Fig. 8, the IFT of surfactant solutions was reduced by increasing dodecanoylglucosamine concentration. The results show this surfactant can reduce the IFT lower than $15 \mathrm{mN} / \mathrm{m}$ by increasing concentration more than $6000 \mathrm{ppm}$. But, the high concentration of surfactant is not applicable in field condition due to high adsorption on rock surface and high price. Therefore, the optimum concentration of this surfactant is considered $800 \mathrm{ppm}$ from $\mathrm{pH}$ and conductivity that reduced IFT to $19 \mathrm{mN} / \mathrm{m}$.
Table 3 The ions concentration in synthetic sea water

\begin{tabular}{lllllll}
\hline Ions & $\mathrm{Cl}^{-}$ & $\mathrm{So}_{4}^{2-}$ & $\mathrm{HCO}_{3}^{-}$ & $\mathrm{Mg}^{2+}$ & $\mathrm{Ca}^{2+}$ & $\mathrm{Na}^{+}$ \\
\hline Con. & 23,000 & 3255 & 165 & 1455 & 325 & 14,000 \\
\hline
\end{tabular}




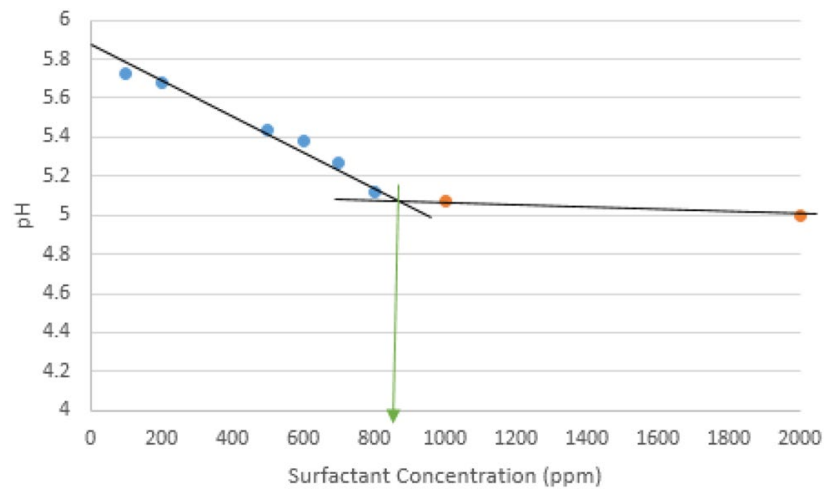

Fig. $6 \mathrm{PH}$ versus surfactant concentration

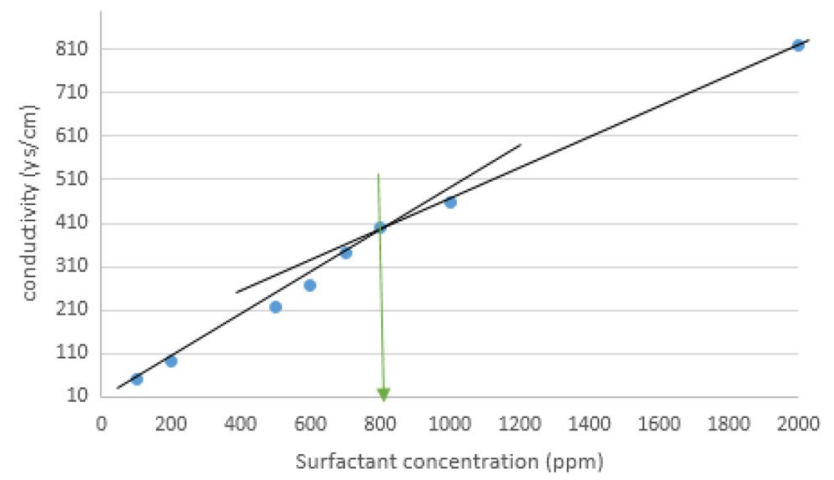

Fig. 7 Conductivity versus surfactant concentration

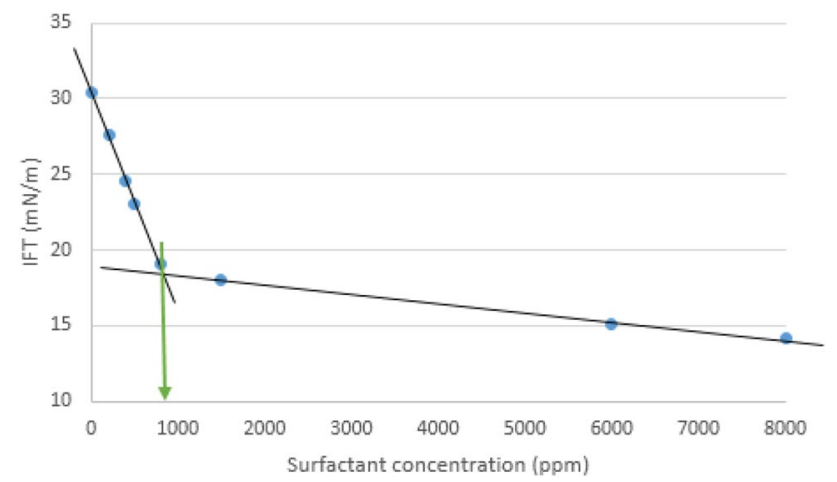

Fig. 8 IFT versus surfactant concentration

Moreover, the effect of surfactant concentration on wettability condition was detected by measuring contact angle. As shown in Fig. 9, the aged pellet was oil wet at first. As shown in Fig. 10 by increasing surfactant concentration, the contact angle was decreased and the wettability condition was alternated from oil wet to water wet. Therefore, the results show dodecanoylglucosamine can reduce IFT and change wettability.

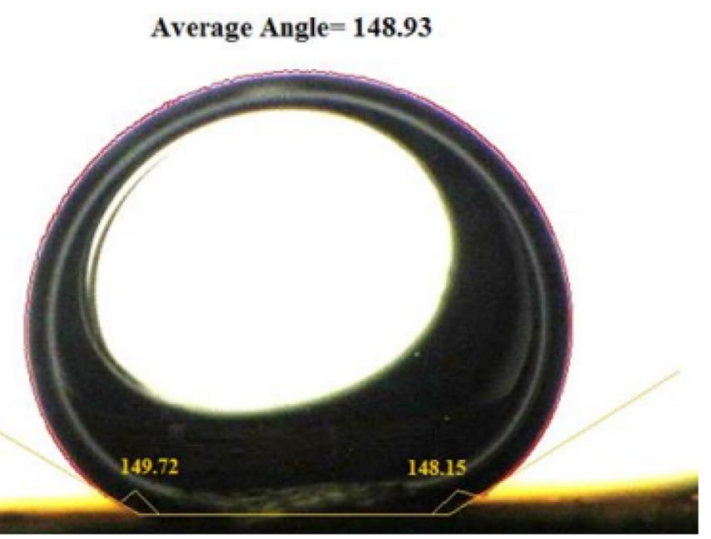

Fig. 9 The contact angle is between a drop of water and a pellet saturated in distilled water

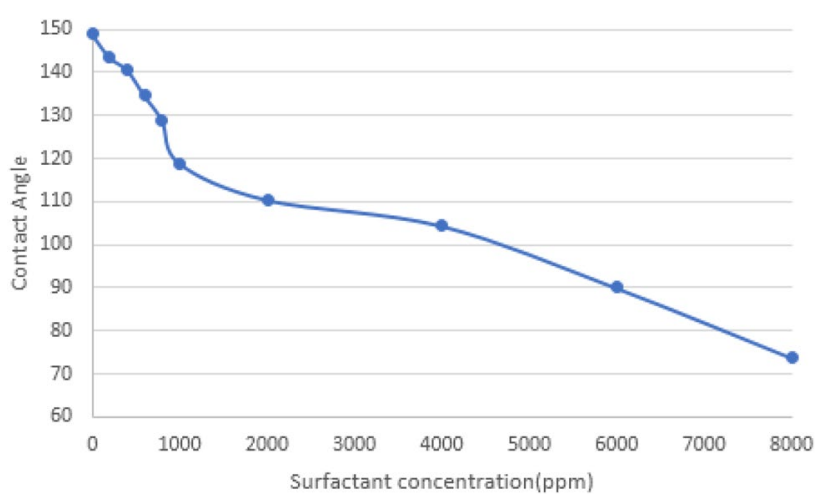

Fig. 10 Contact angle versus surfactant concentration for carbonate pellets

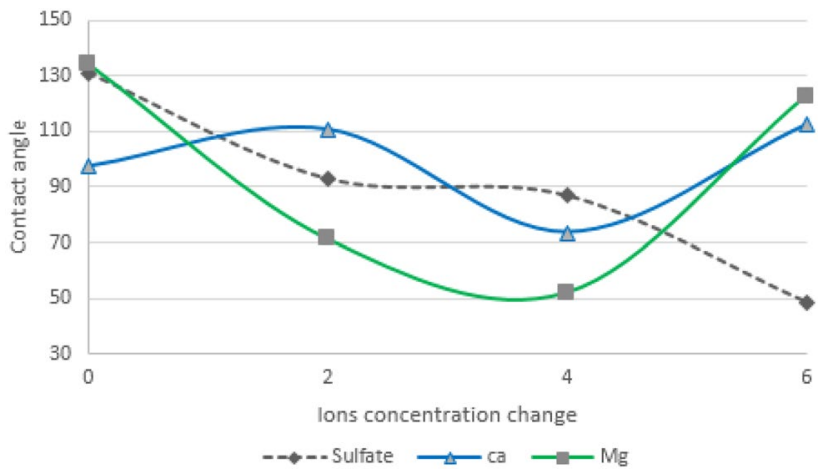

Fig. 11 Contact angle change by modifying the ions concentration in sea water

\section{Smart water behavior}

The contact angle changes were measured by modifying the ions concentration of sea water. As shown in Fig. 11, contact angle was reduced by increasing concentration of $\mathrm{Mg}^{2+}$

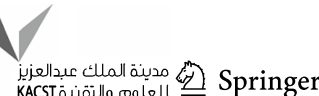


Fig. 12 Contact angle changes based on each ion concentration

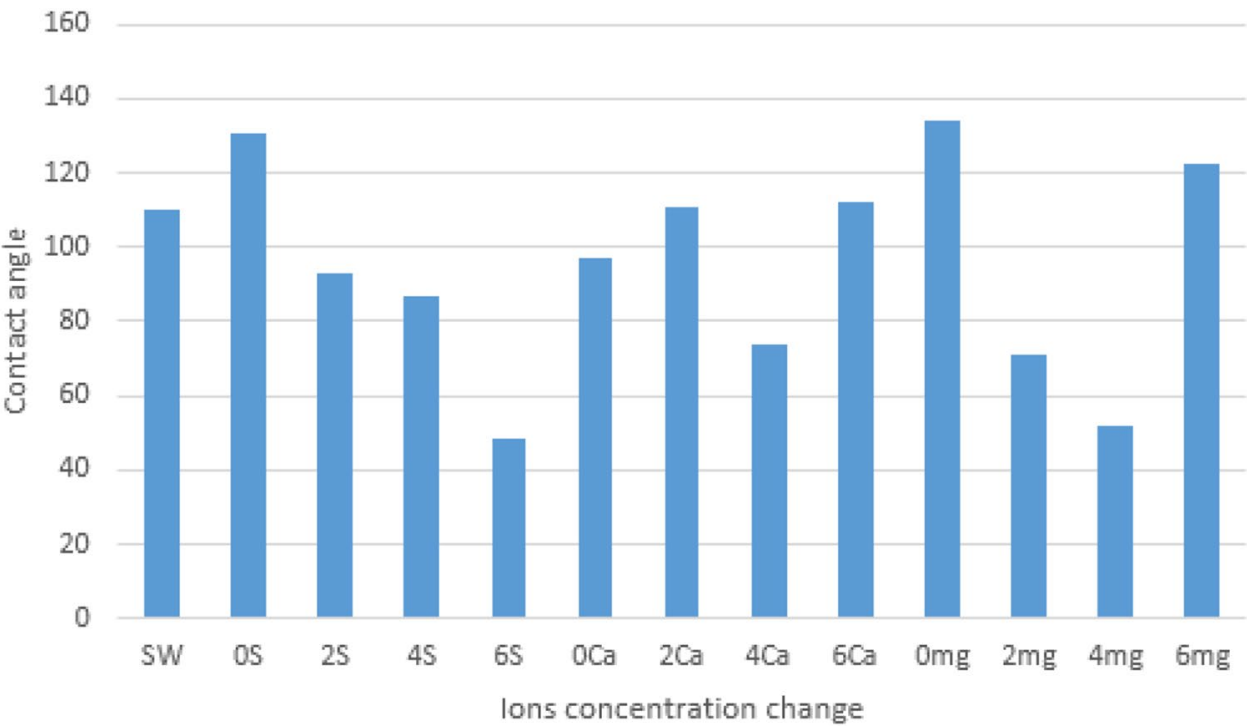

from 0 to 4 times in SW, but increased when it reached 6 times. On the other hand, by increasing the concentration of sulfate ion $\left(\mathrm{So}_{4}^{2-}\right)$ the contact angle was decreased continuously. Moreover, modifying concentration of $\mathrm{Ca}^{2+}$ has different behaviors on contact angle compared to other ions. As shown in Fig. 12, the lowest contact angle was occurred at concentration of $6 \mathrm{So}_{4}^{2-}, 4 \mathrm{Ca}^{2+}$ and $4 \mathrm{Mg}^{2+}$. Moreover, the results show that $\mathrm{So}_{4}^{2-}$ has strong effect on contact angle. This phenomenon can be described in Fig. 4. Therefore, the smart water that obtained by modifying ions from sea water includes $6 \mathrm{So}_{4}^{2-}, 4 \mathrm{Ca}^{2+}$ and $4 \mathrm{Mg}^{2+}$.

\section{Surfactant combination with smart water}

The surfactant solution at concentration of $800 \mathrm{ppm}$ was combined with modified sea water. The contact angle and IFT of some solutions were measured to detect the influence of ions which include $\mathrm{So}_{4}^{2-}, \mathrm{Ca}^{2+}$ and $\mathrm{Mg}^{2+}$ on contact angle when combined with surfactant. As shown in Fig. 13, the IFT of surfactant solutions was decreased by increasing ions concentration. When the surfactant solution was used for IFT reduction, the value of IFT was $19 \mathrm{mN} / \mathrm{m}$ at $800 \mathrm{ppm}$ of dodecanoylglucosamine. But, combination of this surfactant with $6 \mathrm{So}_{4}^{2-}$ reduced the IFT to $11 \mathrm{mN} / \mathrm{m}$. Moreover, the contact angle was decreased by increasing ions concentration. As shown in Fig. 14, the lowest contact angle was occurred at $6 \mathrm{So}_{4}^{2-}$, $6 \mathrm{Ca}^{2+}$ and $6 \mathrm{Mg}^{2+}$ concentration of ions. By comparing this results with pervious results from smart water in last section, it seems the optimum concentration of ions when are combined with surfactant is different from smart water. Because in this condition surfactant and ions change the rock surface wettability condition together. As shown in Fig. 15, the lowest IFT and contact angle were

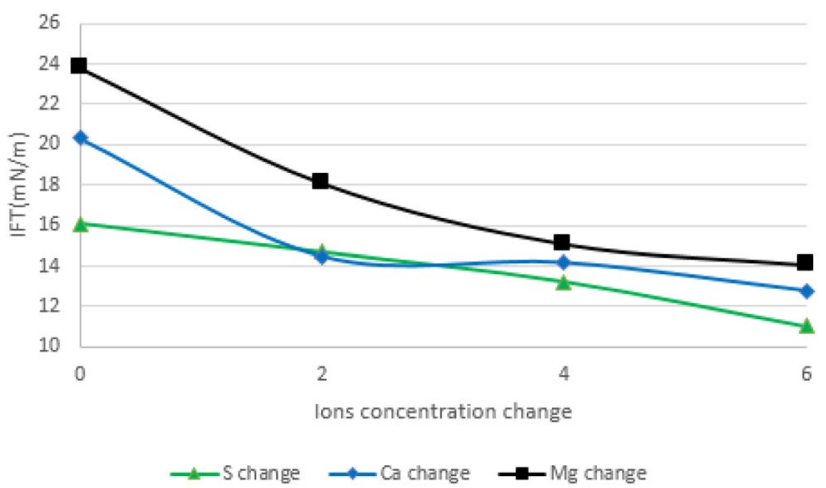

Fig. 13 IFT reduction in combination of surfactant and modified sea water

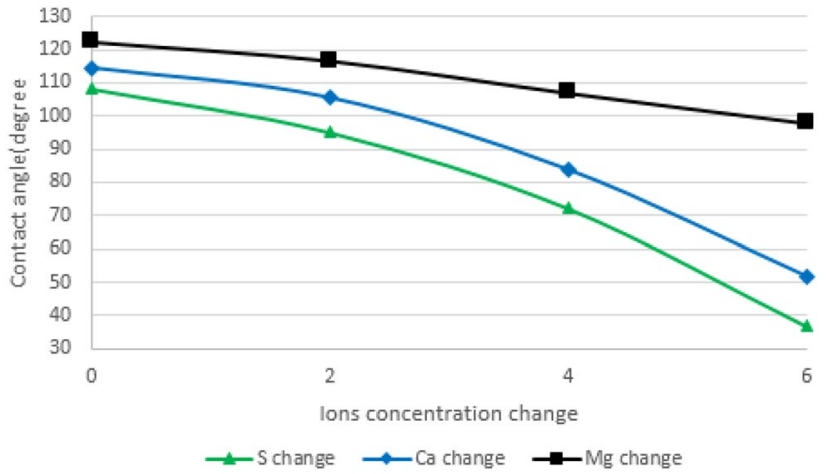

Fig. 14 Contact angle changes by modifying ions concentration in combination of surfactant with modified sea water 
Fig. 15 Contact angle (up) and IFT (down) changes by changing ions concentration with combination by surfactant
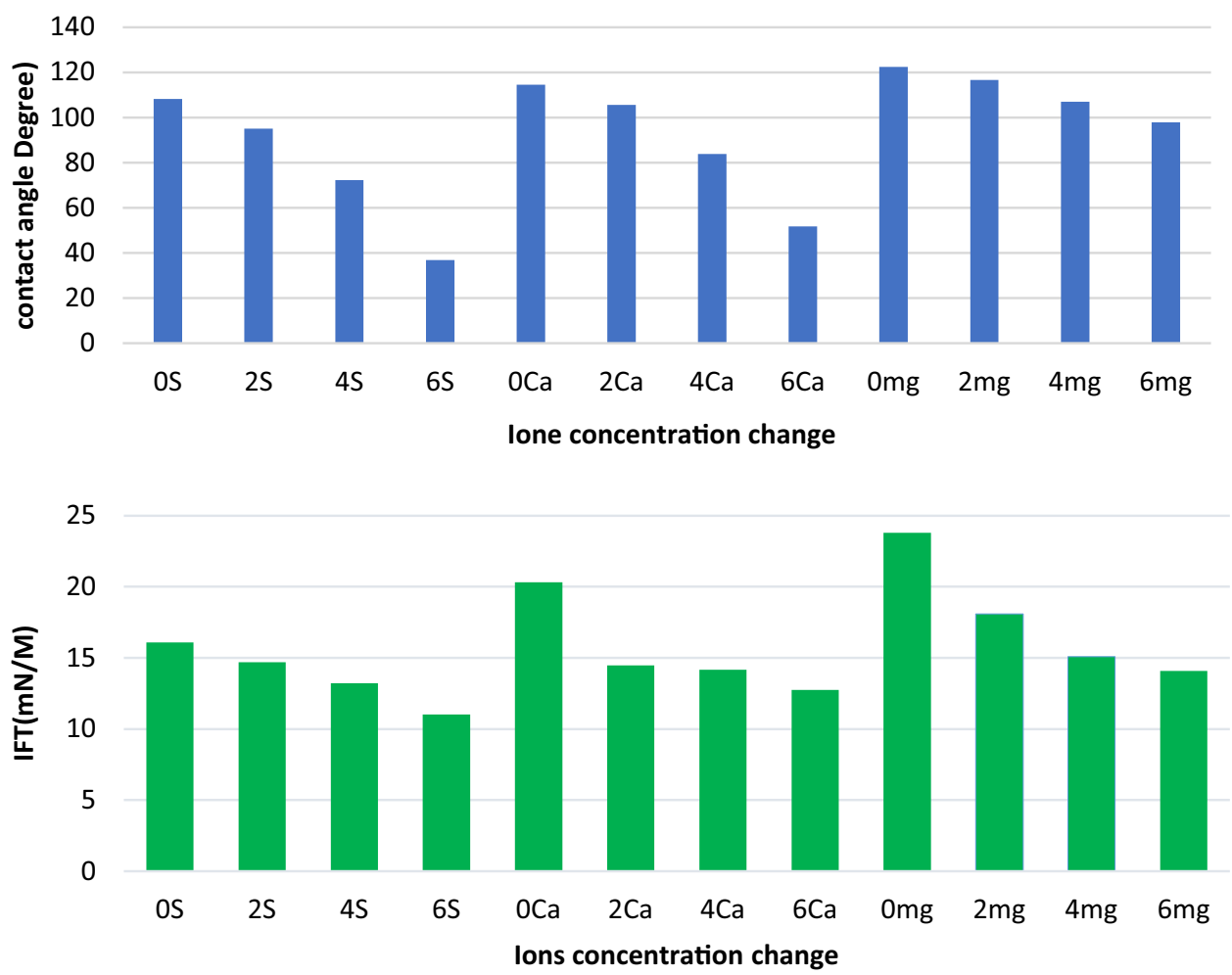

lons concentration change

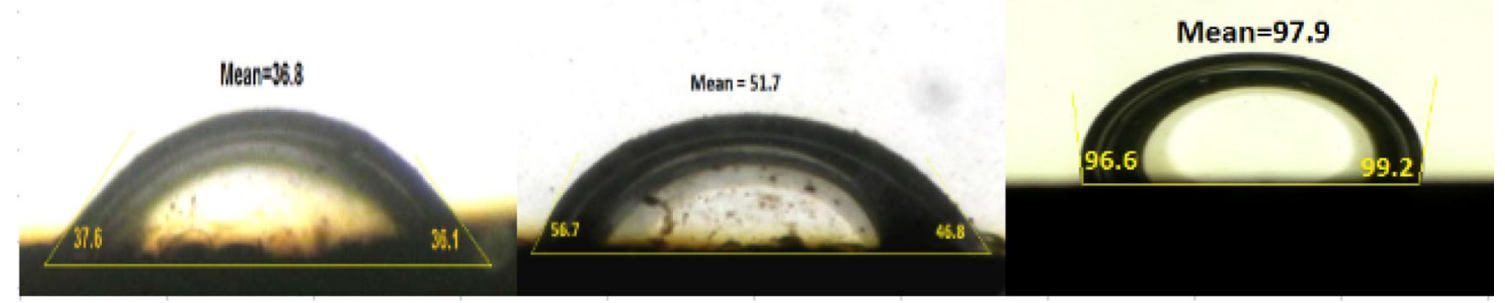

Fig. 16 Contact angle of water drop on rock pellet that was aged in surfactant solution by combination with $6 \mathrm{So}_{4}^{2-}(\mathrm{left}), 6 \mathrm{Ca}^{2+}(\mathrm{middle})$ and $6 \mathrm{Mg}^{2+}$ (right)

occurred at $6 \mathrm{So}_{4}^{2-}, 6 \mathrm{Ca}^{2+}$ and $6 \mathrm{Mg}^{2+}$ concentration by combining with surfactant. Moreover, Fig. 16 shows the contact angle of water drop on rock pellet at this concentration. It is important to note that when the surfactant was used individually for wettability alteration, the contact angle at $800 \mathrm{ppm}$ was 128 . When this surfactant was combined with modified sea water and the concentration of $\mathrm{So}_{4}^{2-}$ was modified to 6 times, the contact angle reached to 48.52 . Therefore, it can be concluded that synergic of dodecanoylglucosamine as surfactant with smart water containing $6 \mathrm{So}_{4}^{2-}$ concentration can be best choice for enhancing oil recovery due to more IFT reduction and wettability alternation.

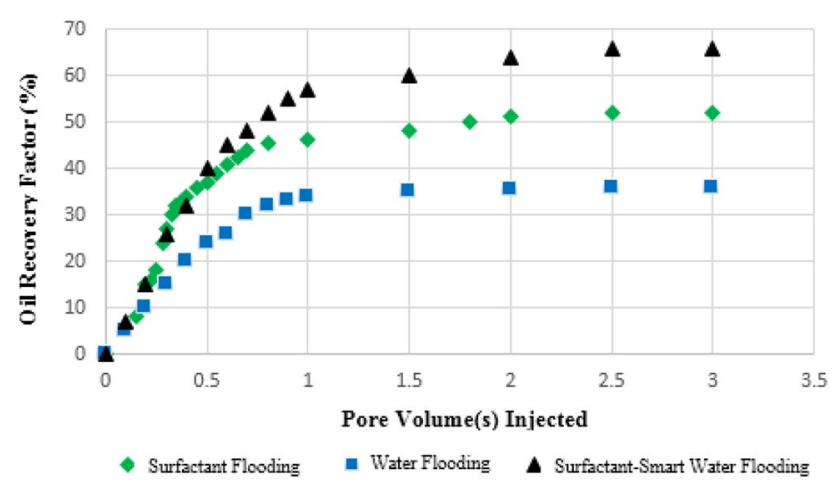

Fig. 17 Oil recovery factor versus pore volume injected during water, surfactant and surfactant-smart water flooding 




Fig. 18 Pressure vs pore volume injected during water, surfactant and surfactant-smart water flooding

\section{Core flooding}

The core flooding was employed to illustrate the effect of surfactant, smart water and mixture of them on wettability alteration and IFT reduction. As shown in Fig. 17, water flooding has lowest oil recovery and high residual oil saturation. In oil-wet carbonate, rock water flooding has low recovery because water leaves the porous media and oil remains in porous. Some surface agent material such as dodecanoylglucosamine reduces the IFT and changes the wettability condition to water wet from oil wet. Therefore, the residual oil saturation was decreased by increasing capillary number and increased oil recovery compared to water flooding. On the other hand, surfactant flooding using smart water flooding with concentration of $6 \mathrm{So}_{4}^{2-}$ increased oil recovery compared to water and surfactant flooding, because synergic of surfactant and $\mathrm{So}_{4}^{2-}$ changed the rock surface condition to more water wet. As shown in Fig. 17, oil recovery after 3 pore volume of injected was 36, 52 and $66 \%$ at the end of water, surfactant and surfactant-smart water flooding, respectively. Therefore, it can be concluded that dodecanoylglucosamine improved oil recover $16 \%$ more than water flooding. On the other hand, combination of dodecanoylglucosamine with smart water enhanced oil recovery $30 \%$ more than water and $14 \%$ more than surfactant flooding. Moreover, the pressure drop during water, surfactant and surfactant-smart water flooding is presented in Fig. 18. It is illustrated that break through was occurred close to 0.5 pore volume injected.

\section{Conclusion}

Enhancing oil recovery in mature oil reservoir is a new challenge in petroleum industry. Chemical enhanced oil recovery method such as surfactant and smart water flooding can be applicable to employ EOR in mature reservoir.
In the present study, feasibility of the dodecanoylglucosamine as new surfactant and combination with smart water was discussed. The main conclusion of this study can be summarized as below:

1. The $\mathrm{CMC}$ of dodecanoylglucosamine based on $\mathrm{pH}$ and conductivity was $800 \mathrm{ppm}$. The results show that dodecanoylglucosamine can be a good choice for surfactant flooding due to IFT reduction from 30.36 to $19 \mathrm{mN} / \mathrm{m}$ at concentration of 0 to $800 \mathrm{ppm}$. Moreover, it can change the wettability by modifying contact angle from 148.93 to 128.87 at concentration of 0 to $800 \mathrm{ppm}$.

2. The results show that modifying ions concentration of sea water can be effective and it can reduce contact angle. Therefore, the smart water was obtained by modifying ions from sea water by concentration of $6 \mathrm{So}_{4}^{2-}$, $4 \mathrm{Ca}^{2+}$ and $4 \mathrm{Mg}^{2+}$. The result shows $\mathrm{So}_{4}^{2-}$ has large effect on contact angle compared to other ions.

3. Making surfactant solution using smart water can be more effective compared to surfactant solution using brine. The results show adding ions in surfactant solution can improve IFT reduction and wettability alteration. The results show making surface solution with $6 \mathrm{So}_{4}^{2-}$ can reduce contact angle from 148.9 to 36.7 . Also, it can reduce IFT from 30.36 to $11 \mathrm{mN} / \mathrm{m}$. Therefore, it can be concluded that combination of surfactant with smart water can help surfactant to be powerful. It was obtained from core flooding test. The core flooding results show combination of surfactant with smart water has more oil recovery compared to surfactant and water flooding.

Open Access This article is distributed under the terms of the Creative Commons Attribution 4.0 International License (http://creativeco mmons.org/licenses/by/4.0/), which permits unrestricted use, distribution, and reproduction in any medium, provided you give appropriate credit to the original author(s) and the source, provide a link to the Creative Commons license, and indicate if changes were made.

\section{References}

Alvarado V, Manrique E (2010) Enhanced oil recovery: an update review. Energies 3(9):1529-1575

Awolayo A, Sarma H, AlSumaiti AM (2014) A laboratory study of ionic effect of smart water for enhancing oil recovery in carbonate reservoirs. In: SPE EOR conference at oil and gas West Asia. Society of Petroleum Engineers

Bagrezaie MA, Peyman P (2015) Improvment of surfactant flooding performance by application of nanopartivle in sandstone reservoirs. J Jpn Petrol Inst 58(2):97-102

Emadi S, Shadizadeh SR, Manshad AK, Rahimi AM, Mohammadi AH (2017) Effect of nano silica particles on interfacial tension (IFT) and mobility control of natural surfactant (CEDR extraction) 
solution in enhanced oil recovery process by nano-surfactant flooding. J Mol Liq 248:163-167

Fathi SJ, Austad T, Strand S (2010) 'Smart water' as a wettability modifier in chalk: the effect of salinity and ionic composition. Energy Fuels 24(4):2514-2519

Fathi SJ, Austad T, Strand S (2012) Water-based enhanced oil recovery (EOR) by "smart water" in carbonate reservoirs. In: SPE EOR conference at oil and gas West Asia. Society of Petroleum Engineers

Firozjaii AM, Derakhshan A, Shadizadeh SR (2018) An investigation into surfactant flooding and alkaline-surfactant-polymer flooding for enhancing oil recovery from carbonate reservoirs: experimental study and simulation. Energy Sources Part A Recovery Util Environ Eff 40(24):2974-2985

Ghahfarokhi AK, Dadashi A, Daryasafar A, Moghadasi J (2015) Feasibility study of new natural leaf-derived surfactants on the IFT in an oil-aqueous system: experimental investigation. J Petrol Explor Prod Technol 5(4):375-382

Hirasaki G, Zhang DL (2004) Surface chemistry of oil recovery from fractured, oil-wet, carbonate formations. SPE J 9(02):151-162

Kathel P, Mohanty KK (2013) EOR in tight oil reservoirs through wettability alteration. In: SPE annual technical conference and exhibition. Society of Petroleum Engineers

Ligthelm DJ, Gronsveld J, Hofman J, Brussee N, Marcelis F, van der Linde H (2009) Novel waterflooding strategy by manipulation of injection brine composition. In: EUROPEC/EAGE conference and exhibition. Society of Petroleum Engineers

Mehdi R, Milad M, Reza S, Amin D (2015) Effect of natural leafderived surfactants on wettability alteration and interfacial tension reduction in water-oil system: eOR application. J Jpn Petrol Inst 58(4):245-251

Mittal KL (2009) Contact angle, wettability and adhesion, vol 6. CRC Press, Boca Raton

Mohsenatabar Firozjaii A, Akbari M, Zargar G (2019) Sensitivity analysis and optimization on effective parameters during chemical enhanced oil recovery (CEOR) using experimental design and numerical simulation. Energy Source Part A: Recover Util Environ Eff 41(15):1847-1861

Mosalman Haghighi O, Ghassem Z, Siyamak M, Takkasi MA, Manshad AK (2018) Experimental investigation ofeffect of new green nonionic surfactant on wettability alteration in EOR process. Petroleum University of Technology, Abadan, Iran

Omid MH, Zargar G, Moradi S, Takkasi MA, Kaksar MA (2018) Experimental investigation of effect of new green nonionic surfactant on wettability alteration in EOR process. Petroleum University of Technology, Abadan, Iran

Onyekonwu MO, Ogolo NA (2010) Investigating the use of nanoparticles in enhancing oil recovery. In: Nigeria annual international conference and exhibition. Society of Petroleum Engineers

Puerto MC (2001) Surfactants: fundamentals and applications in the Petroleum Industry-Cambridge University Press, 2000, Pp. 621,@ \$85.00 (US \$140.00)(Hardback), ISBN 0-521-64067-9. Chem Eng J 1(83):63

Puntervold T, Strand S, Ellouz R, Austad T (2015) Modified seawater as a smart EOR fluid in chalk. J Petrol Sci Eng 133:440-443

Rellegadla S, Prajapat G, Agrawal A (2017) Polymers for enhanced oil recovery: fundamentals and selection criteria. Appl Microbiol Biotechnol 101(11):4387-4402
RezaeiDoust A, Puntervold T, Strand S, Austad T (2009) Smart water as wettability modifier in carbonate and sandstone: a discussion of similarities/differences in the chemical mechanisms. Energy Fuels 23(9):4479-4485

SayedAkram NI, Mamora D (2011) Simulation study on surfactantpolymer flood performance in fractured carbonate reservoir. In: SPE/DGS Saudi Arabia section technical symposium and exhibition. Society of Petroleum Engineers

Seethepalli A, Adibhatla B, Mohanty KK (2004) Wettability alteration during surfactant flooding of carbonate reservoirs. In: SPE/ DOE symposium on improved oil recovery. Society of Petroleum Engineers

Shah DO (2012) Improved oil recovery by surfactant and polymer flooding. Elsevier, Amsterdam

Sheng J (2010) Modern chemical enhanced oil recovery: theory and practice. Gulf Professional Publishing, Burlington

Strand AT (2003) Spontaneous imbibitions of aqueous surfactant solutions into neutral to oil-wet carbonate cores: effects of brine salinity and composition. Energy Fuels 17:1133-1144

Strand S, Austad T, Puntervold T, Høgnesen EJ, Olsen M, Barstad SMF (2008) 'Smart water' for oil recovery from fractured limestone: a preliminary study. Energy Fuels 22(5):3126-3133

Sun X, Zhang Y, Chen G, Gai Z (2017) Application of nanoparticles in enhanced oil recovery: a critical review of recent progress. Energies 10(3):345

Tang G-Q, Morrow NR (1999) Influence of brine composition and fines migration on crude oil/brine/rock interactions and oil recovery. J Petrol Sci Eng 24(2-4):99-111

Webb KJ, Black CJJ, Tjetland G (2005) A laboratory study investigating methods for improving oil recovery in carbonates. In: International petroleum technology conference. International Petroleum Technology Conference

Xie X, Weiss WW, Tong ZJ, Morrow NR (2005) Improved oil recovery from carbonate reservoirs by chemical stimulation. SPE J 10(03):276-285

Yousef AA, Al-Saleh S, Al-Jawfi MS (2011) Smart waterflooding for carbonate reservoirs: salinity and role of ions. In: SPE middle east oil and gas show and conference. Society of Petroleum Engineers

Zhang P, Tweheyo MT, Austad T (2007) Wettability alteration and improved oil recovery by spontaneous imbibition of seawater into chalk: impact of the potential determining ions $\mathrm{Ca}^{2+}, \mathrm{Mg}^{2+}$, and $\mathrm{SO}_{4}{ }^{2-}$. Colloids Surf A Physicochem Eng Asp 301(1-3):199-208

Zhang F, Saputra IWR, Adel IA, Schechter DS (2018) Scaling for wettability alteration induced by the addition of surfactants in completion fluids: surfactant selection for optimum performance. In: Unconventional resources technology conference, Houston, Texas, 23-25 July 2018. SEG Global Meeting Abstracts. Society of Exploration Geophysicists, American Association of Petroleum Geologists, Society of Petroleum Engineers, pp 971-987. https:// doi.org/10.15530/urtec-2018-2889308

Publisher's Note Springer Nature remains neutral with regard to jurisdictional claims in published maps and institutional affiliations. 